\title{
Analisis Komunikasi Pemasaran Terpadu PT. Cubes Consulting dalam Membangun Brand Association
}

\author{
Sherly Margaretha, Widayatmoko, M. Adi Pribadi \\ Sherly Margaretha adalah alumnus Fakultas Ilmu Komunikasi Universitas \\ Tarumanagara. \\ Widayatmoko dan M. Adi Pribadi adalah dosen Fakultas Ilmu Komunikasi \\ Universitas Tarumanagara
}

\begin{abstract}
Abstrak
Penelitian ini membahas tentang komunikasi pemasaran terpadu yang dilakukan oleh PT Cubes Consulting untuk membangun brand image dari perusahaan tersebut. Penulis mengambil topik ini karena penulis beranggapan bahwa PT Cubes Consutting sebagai partner SAP, merupakan perusahaan yang masih sangat baru, tetapi sudah bisa memiliki referensi client yang cukup banyak dan berasal dari perusahaan besar. Padahal persaingan di dunia bisnis ini tidaklah mudah, karena banyak juga partner SAP di Indonesia yang sudah terlebih dahulu terjun ke dunia ini dan dilihat dari ukuran bisnis, jelas lebih besar.
\end{abstract}

Kata Kunci: Brand Image, Produk, Komunikasi Pemasaran Terpadu

\section{Abstract}

This study discusses the integrated marketing communications conducted by PT Cubes Consulting to build the brand image of the company. Authors take this subject because the authors assume that the PT Cubes Consutting as an SAP partner, a company that is still very new, but it could have a considerable client references and come from large companies. Though competition in the business world is not easy, because many SAP partners in Indonesia who have first foray into the world and be seen from the size of the business, obviously bigger.

Keywords: Brand Image, Product,Integrated Marketing Communications

\section{Pendahuluan}

Munculnya perusahaan-perusahaan, baik dari perusahaan industri, perusahaan perdagangan, maupun perusahaan jasa membuat peranan komunikasi semakin erat hubungannya dengan kemajuan setiap perusahaan. Sebuah perusahaan adalah sebuah institusi yang sangat kompleks dimana terdapat banyak individu yang memiliki pemikiran berbeda dan dibatasi dengan hirarki dan jabatan tertentu. Dengan melakukan kegiatan komunikasi yang beragam, baik itu tertulis maupun tidak tertulis, sebuah perusahaan dapat menginformasikan target konsumen mengenai fungsi dari produk yang mereka jual. Kegiatan komunikasi yang memiliki tujuan memasarkan produk ini disebut juga sebagai komunikasi pemasaran. 
Seiring dengan perkembangan waktu, muncul juga sebuah studi mengenai komunikasi pemasaran terpadu, dimana kegiatan ini merupakan sebuah perencanaan kegiatan komunikasi pemasaran untuk mencapai tujuan tertentu sebuah perusahaan. Kegiatan komunikasi pemasaran terpadu ini diharapkan dapat membangung brand image dari sebuah perusahaan. Brand image ini dianggap penting juga karena artinya perusahaan atau produk memiliki label tersendiri di benak konsumen mengenai kemampuan, kelebihan, ataupun kelemahan yang dimiliki.

Sebagaisebuah perusahaan,PTCubes Consulting (CUBES) juga menjalankan kegiatan komunikasi pemasaran terpadu dalam perjalanan bisnis mereka. Sebagai salah satu perusahaan penyedia barang dan jasa, CUBES harus mampu untuk menarik minat perusahaan-perusahaan tertentu untuk mau menggunakan layanan jasa yang ditawarkan. CUBES sendiri bergerak sebagai partner resmi SAP AG (Systems, Applications, and Products in Data Processing), membantu SAP sebagai principal dalam mengimplementasikan produk software dan penjualan license di perusahaan-perusahaan yang membutuhkan.

CUBES harus mampu mempertahankan kesetiaan konsumen yang sudah pernah bekerjasama dengan CUBES, sehingga saat mereka membutuhkan jasa lagi mereka akan tetap memanggil CUBES sebagai partner bisnis mereka. Dalam membangun perusahaan, CUBES harus dapat membangun brand image mereka dimata konsumen, sehingga saat konsumen menginginkan adanya implementasi di perusahaan mereka, nama CUBES lah yang akan muncul pertama di benak mereka.

Pembahasan mengenai komunikasi pemasaran terpadu sudah pasti tidak akan lepas dari elemen pembangun kegiatan tersebut, yaitu komunikasi, pemasaran, komunikasi pemasaran, dan komunikasi pemasaran terpadu itu sendiri. Sedangkan, untuk pembahasan mengenai brand image, harus dipahami pula definisi dari brand dan brand image itu sendiri

Dalam penulisan ini, penulis menggunakan beberapa teori yang relevan dan dapat mendukung pembahasan mengenai komunikasi pemasaran terpadu CUBES dalam rangka membangun brand image. Pertama adalah pengertian komunikasi, seperti yang diungkapkan oleh Carl. I. Havland dalam buku Ilmu Komunikasi : Sebuah Pengantar (2001 : 48), yang dikutip oleh Deddy Mulyana, bahwa komunikasi adalah proses yang memungkinkan seseorang (komunikator) menyampaikan rangsangan untuk mengubah perilaku orang lain (komunikan).

Pengertian pemasaran menurut William J. Stanton (2001:4) dalam buku Prinsip-Prinsip Pemasaran adalah suatu sistem total dari kegiatan bisnis yang dirancang untuk merencanakan, menentukan harga, mempromosikan dan mendistribusikan barang-barang yang dapat memuaskan keinginan dan jasa baik kepada konsumen saat ini maupun konsumen potensial. Penggabungan dari dua kajian: pemasaran dan komunikasi menghasilkan kajian baru yang diberi nama komunikasi pemasaran (marketing communication). 
Djasmin Saladin (2003:123) dalam buku Manajemen Pemasaran, mengungkapkan komunikasi pemasaran adalah aktivitas yang berusaha menyebarkan informasi, mempengaruhi dan membujuk atau mengingatkan pasar sasaran atas perusahaan dan produknya agar bersedia menerima, membeli, loyal pada produk yang ditawarkan perusahaan yang bersangkutan. Komunikasi pemasaran merupakan bentuk komunikasi yang ditujukan untuk memperkuat strategi pemasaran, guna meraih segmentasi yang lebih luas. Dalam komunikasi pemasaran ada yang disebut sebagai marketing communication mix, yang terdiri dari advertising, sales promotion, events and experiences, public relation and publicity, interactive marketing, direct marketing, word-of-mouth marketing, dan personal selling. (Kotler \& Keller, 2012:60)

Setelah memahami konsep dari kegiatan komunikasi pemasaran, baru dapat masuk ke dalam kegiatan komunikasi pemasaran terpadu atau biasa dikenal sebagai integrated marketing communication (IMC). Shimp (2003:24) dalam buku "Periklanan Promosi Aspek Tambahan Komunikasi Pemasaran Terpadu", mengutip definisi IMC dari Don E. Shultz (1993:17) bahwa IMC adalah proses pengembangan dan implementasi berbagai bentuk program komunikasi persuasif kepada pelanggan dan calon pelanggan secara berkelanjutan. Lebih jauh lagi, IMC menggunakan semua bentuk komunikasi yang relevan serta yang dapat diterima oleh pelanggan dan calon pelanggan. Dengan kata lain, proses IMC berawal dari pelanggan atau calon pelanggan, kemudian berbalik kepada perusahaan untuk menentukan dan mendefinisikan bentuk dan metode yang perlu dikembangkan bagi program komunikasi yang persuasif.

\section{Brand}

Pengertian brand menurut David A. Aaker (1997:8) dalam buku Managing Brand Equity: Capitalizing on the Value of a Brand Name adalah nama dan atau simbol yang bersifat membedakan (seperti sebuah logo,cap atau kemasan) dengan maksud mengidentifikasi barang atau jasa dari seorang penjual atau sebuah kelompok penjual tertentu. Faktor yang perlu ada untuk membedakannya dari pesaing adalah harus disertai dengan janji dalam bentuk features, benefits, dan service kepada konsumen. Dengan demikian suatu brand membedakannya dari barang atau jasa yang dihasilkan oleh competitor.

Penelitian kali ini mencoba untuk mengkaitkan antara IMC dalam peranannya membangun sebuah brand image perusahaan, sehingga harus dipahami juga konsep dari brand image itu sendiri. William J. Stanton (1996:269) mendefinisikan brand sebagai' nama, istilah, simbol atau slogan khusus atau beberapa kombinasi unsur-unsur ini yang dirancang untuk mengidentifikasi barang atau jasa yang ditawarkan oleh penjual. Ekuitas merek berbeda dari konteks yang satu ke konteks yang lainnya, yang dapat dikategorikan dalam lima kelompok, yaitu brand loyalty (loyalitas merek), brand Awareness (kesadaran merek), perceived quality (kesan kualitas), dan brand association (asosiasi merek). Terence A Shimp (2003:12) mengatakan usaha yang paling sering dilakukan untuk membangun brand adalah melalui program pemasaran dan komunikasi 
pemasaran, agar tercipta asosiasi yang mendukung, kuat, dan unik di benak konsumen antara merek dengan atribut/ manfaatnya. Produk yang memiliki kualitas tinggi dan mempresentasikan nilai yang baik secara potensial mempunyai ekuitas merek yang tinggi. Namun, dibutuhkan usaha komunikasi pemasaran yang efektif dan konsisten untuk membangun dan mempertahankan ekuitas merek.

Terence A Shimp (2003:12), dalam buku Periklanan Promosi Aspek Tambahan Komunikasi Pemasaran Terpadu, mengatakan bahwa citra merek (brand image) dapat dianggap sebagai jenis asosiasi yang muncul di benak konsumen ketika mengingat sebuah merek tertentu. Asosiasi tersebut secara sederhana dapat muncul dalam bentuk pemikiran atau citra tertentu yang dikaitkan kepada suatu merek, sama halnya ketika kita berpikir mengenai orang lain. Menurut Keller (2003:56) dalam buku Strategic Brand Management, ada 3 faktor pendukung terbentuknya brand image dalam keterkaitannya dengan asosiasi merek, yaitu Favorability of brand association/ Keunggulan asosiasi merek, strength of brand association/ Familiarity of brand association/ Kekuatan asosiasi merek, dan uniqueness of brands association/ Keunikan asosiasi merek.

\section{Metode Analisis}

Data yang digunakan dalam penelitian ini ada dua yaitu data primer dan data sekunder. Data primer dalam penelitian ini didapat melalui wawancara yang mendalam terhadap nara sumber yang berkompeten baik dari CUBES sebagai perusahaan maupun dari perusahaan klien yang sudah pernah ditangani oleh CUBES. Wawancara penulis dari pihak CUBES adalah Ray Montha selaku Operation Director dan Ceasarianto Rahardjo selaku Sales Manager, dan dari pihak client Kemal Alfadin selaku GM Supply Chain Management PT Hasnur dan IT Manager Sinar Mas Mining. Selain menggunakan wawancara mendalam, dalam penelitian ini penulis juga menggunakan teknik participant observation.

Data sekunder yang digunakan didapat dari studi kepustakaan dan internet. Dengan teknologi yang semakin canggih, penulis memanfaatkan internet dalam mencari bahan yang dibutuhkan dalam penelitian ini. Dikarenakan pengetahuan mengenai produk yang dijual oleh perusahaan ada di official website dari SAP, sehingga informasi dapat diambil dari web tersebut.

\section{Pembahasan}

CUBES adalah salah satu Channel dan Service Partner SAP di Indonesia yang menyediakan jasa teknologi informasi di bagian implementasi software, menyediakan aplikasi support dan pelatihan. CUBES berkomitmen untuk membantu implementasi SAP untuk mengimprovisasi performa dan efisiensi bisnis dari sebuah perusahaan.

Selain menyediakan SAP sebagai produk, CUBES juga menyediakan jasa berupa para consultant untuk melakukan implementasi di perusahaan-perusahaan yang membutuhkan. CUBES sebagai salah satu partner SAP memang lebih berkonsentrasi pada penyediaan jasa implementasi dan pelatihan. Tanpa adanya consultant, penjualan SAP sendiri 
dalam bentuk license akan mengalami hambatan, sehingga antara barang dan jasa dalam dunia SAP memiliki hubungan yang sangat erat.

Setiap perusahaan pastinya akan melakukan kegiatan pemasaran atas produk atau jasa yang mereka jual. Tugas besar dari perusahaan adalah mengkomunikasikan barang yang mereka jual kepada konsumennya. Djasmin Saladin (2003:123) dalam buku Manajemen Pemasaran, mengungkapkan komunikasi pemasaran adalah aktivitas yang berusaha menyebarkan informasi, mempengaruhi dan membujuk atau mengingatkan pasar sasaran atas perusahaan dan produknya agar bersedia menerima, membeli, loyal pada produk yang ditawarkan perusahaan yang bersangkutan.

SAP sebagai produk satu-satunya yang dijual oleh CUBES, merupakan sebuah produk yang tidak terlihat dan CUBES sendiri menjual jasa implementasi SAP di perusahaan-perusahaan yang juga sebenarnya, jasa implementasi bukanlah barang yang dapat dilihat atau dirasakan. Pendekatan-pendekatan yang dilakukan oleh CUBES kepada konsumennya berbeda dengan pendekatan-pendekatan yang dilakukan oleh perusahaan yang menjual produk yang terlihat. CUBES harus bisa datang ke satu-satu konsumennya untuk bisa memberikan informasi mendetail tentang produk yang mereka jual. Target market dari CUBES, bukan lah perorangan, melainkan ke perusahaan yang sudah pasti memiliki jenjang pengambilan keputusan yang bertingkat.

Shimp (2003:24) dalam buku Periklanan Promosi Aspek Tambahan
Komunikasi Pemasaran Terpadu, mengutip definisi IMC dari Don E. Shultz (1993:17) bahwa IMC adalah proses pengembangan dan implementasi berbagai bentuk program komunikasi persuasif kepada pelanggan dan calon pelanggan secara berkelanjutan. Dari definisi mengenai IMC ini, jelas bahwa IMC juga dilakukan di CUBES, dimulai dari mencari pelanggan, melakukan negosiasi sampai akhirya terjadilah kesepakatan antara CUBES dengan client-nya. Lebih jauh lagi, Don E. Shultz (1993:17) menjelaskan bahwa IMC menggunakan semua bentuk komunikasi yang relevan serta yang dapat diterima oleh pelanggan dan calon pelanggan. Dari hasil penelitian yang penulis lakukan di CUBES, dimana CUBES juga berperan sebagai sales di perusahaan tersebut, penulis melihat bahwa CUBES juga melakukan beberapa bentuk komunikasi pemasaran yang dilakukan dalam proses mencari client.

Dalam kaitannya dengan brand image, CUBES menggunakan IMC untuk bisa membangun brand imange CUBES di benak konsumen. Bagi konsumen CUBES, yang akan diingat oleh mereka adalah pengalaman implementasi, cara menjelaskan mengenai produk, harga yang kompetitif, dan consultant yang kompeten. Kesan baik yang menempel pada setiap costumer akan bisa membawa CUBES ke project lainnya. Saat berjalannya project, time project dan tim sales tidak hanya akan berhubungan dengan satu divisi saja, melainkan banyak divisi dengan tingkatan yang berbeda, mulai dari karyawan biasa sampai dengan pemilik perusahaan. Maka dari itu, CUBES harus bisa menjalankan dan menyelesaikan project sebaik mungkin 
untuk dapat mendukung penjualan ke depannya.

\section{Simpulan}

Kegiatan komunikasi pemasaran terpadu yang dilakukan oleh CUBES dalam membangun brand image di mata konsumen, memang tidak mencakup semua kegiatan yang ada menurut teori yang dikemukakan oleh Kotler Keller. Sampai saat ini CUBES melakukan 7 kegiatan, yaitu advertising yang dibantu oleh SAP, direct marketing, personal selling, interactive marketing, sales promotion, events and experiences, dan word-of-mouth marketing. Dengan menggabungkan ketujuh kegiatan ini, CUBES mampu menemukan konsumen yang tepat untuk menjual license SAP dan jasa implementasinya. Kegiatan yang paling banyak dimaksimalkan justru ada pada kegitan personal selling, dengan mengerahkan kemampuan dari personal sales dan consultant yang dimiliki. Dalam hal pembangunan brand image tentunya ketujuh kegiatan ini juga membantu mengkomunikasikan brand image yang dimiliki oleh CUBES.

Rumitnya produk SAP, membuat pendekatan yang dilakukan oleh CUBES ke konsumen lebih bersifat personal dan one-to-one, sehingga penyampaian pesan akan lebih konsisten dari waktu ke waktu. Pembuatan iklan di media massa dianggap tidak efektif karena tidak dapat membuat client dengan mudah dapat memilih CUBES sebagai partner mereka. Brand image yang dibangun lewat kegiatan komunikasi pemasaran lebih berpengaruh dari pengalaman implementasi yang sudah pernah CUBES jalani dan juga rekomendarsi dari berbagai pihak yang pernah melakukan implementasi bersama CUBES atau memang mengetahui kinerja CUBES.

Fungsi sales CUBES dalam mengelola komunikasi pemasaran terpadu telah dilaksanakan berdasar pada kebutuhan konsumen dan perencanaan yang dilakukan di awal, sampai proses negosiasi yang dapat mengubah level diskon dan memberikan tawarantawaran tertentu agar client merasa CUBES memberikan penawaran terbaik untuk memenuhi kebutuhan mereka.

Untuk meningkatkan brand image dan penjualan CUBES, perlu adanya tambahan tenaga dan pelatihan yang baik bagi para sales CUBES. Setiap sales perlu memiliki dasar yang sama saat melakukan penjualan ke costumer dan dapat menjelaskan SAP secara teknis dan tidak hanya berbicara mengenai lapisan luar dari SAP saja, tapi bisa masuk sampai ke business process sebuah perusahaan.

CUBES perlu juga untuk ikut serta dalam kemajuan media social, untuk mempertegas keberadaannya di dunia SAP. Dengan menggunakan new media ini pula akan membuat semakin banyak orang yang menyadari adanya CUBES.

\section{DAFTAR PUSTAKA}

Aaker, David A., (1996). Managing Brand Equity. New York : Maxwell Macmilan Inc.

Effendy, Onong Ucjana, (2003). Ilmu Teori, dan Filasafat Komunikasi. Bandung : Citra Aditya Bakti. 
Eswasta, Basu, (2000) Asas-Asas Marketing. Yoyakarta : Liberty

Grewal, Dhruv, Michael Levy, (2010). Marketing. Second Edition. New York: The McGraw-Hill Companies, Inc.,

Kartono, Kartini, (1990). Pengantar Metodologi Riset Sosial, Bandung: Mandar Maju.

Kotler, Philip \& Amstrong, G. (2001). Dasar-Dasar Pemasaran. Edisi Kesembilan. Jilid Satu. Jakarta : PT Indeks.

Kotler, Philip \& Armstrong, Gary, (2001). Principles of Marketing. Tenth Edition. New Jersey: Pearson Prentice Hall.

Kotler, P. \& Keller, K. L. (2012). Marketing Management. 14th Edition. New Jersey : Pearson Education, Inc.

Kriyantono, Rachmat, (2006). Teknik Praktis Riset Komunikasi, Jakarta: Kencana Prenada Group

Kusmayadi dan Sugiarto, Endar, (2000). Metode Penelitian Kepariwisataan. Jakarta: PT Gramedia Pusataka Utama.

Moleong, L. J. (2004). Metodologi Penelitian Kualitatif. Bandung : PT Remaja Rosdakarya.

Mulyana, Deddy. (2001). Ilmu Komunikasi Suatu Pengantar. Bandung: PT Remaja Rosda Karya.

Nystrom, H. (2001). Ruang Lingkup Manajemen Pemasaran. Jakarta : Erlangga.

Onong Effendy, (1994), Ilmu Komunikasi: Teori dan Praktek. Bandung: PT Remaja Rosda Karya.
Poerwandari, E.K. (2005). Pendekatan Kualitatif untuk Penelitian Perilaku Manusia. Jakarta: Lembaga Pengembangan Sarana Pengukuran dan pendidikan Psikologi Fakultas Psikologi Universitas Indonesia.

Rakhmat, Jalaludin. (2002). Psikologi Komunikasi. Edisi Revisi. Bandung: PT. Remaja Rosdakarya.

Rossiter, John R. dan Larry Percy. (1997). Advertising and Promotion Management. New York: McGrawHill.

Ruben, B.D., \& Lea P. Stewart. (1998). Communication and Human Behavior. Needham Heights: A Viacom Company.

Ruslan, Rosady. (2001). Etika Kehumasan, Konsepsi dan Aplikasi. Jakarta : Raja Grafindo Persada.

Ruslan, Rusady. (2006). Manajemen Humas dan Komunikasi, Konsepsi dan Aplikasi. Jakarta : PT. Rajagrafindo Persada.

Saladin Djaslim, (2003). Manajemen Pemasaran : Analisis, Perencanaan, Pelaksanaan, dan Pengendalian. Edisi Kedua. Bandung : CV. Linda Karya.

Shimp, A Terence. (2003). Periklanan Promosi. Jakarta : Erlangga

Soemanagara. (2006). Strategic Marketing Communication. Bandung : CV. Alfabeta.

Stanton, William, J., (2001), Prinsip-prinsip Pemasaran. Jilid Ketujuh. Jakarta: Erlangga.

Vivian, John.2008. Teori Komunikasi Massa. Jakarta: Kencana Prenada Media Group 
Yeshin, T. (1998). Integrated Marketing Communications: The Holistic Approach. Great Britain: Biddles Ltd.
Yin, Robert K. (2003). Studi Kasus: Disain dan Metode. M. Djauzi Mudjakir (Penerjemah). Jakarta : PT. Raja Grafindo Persada. 